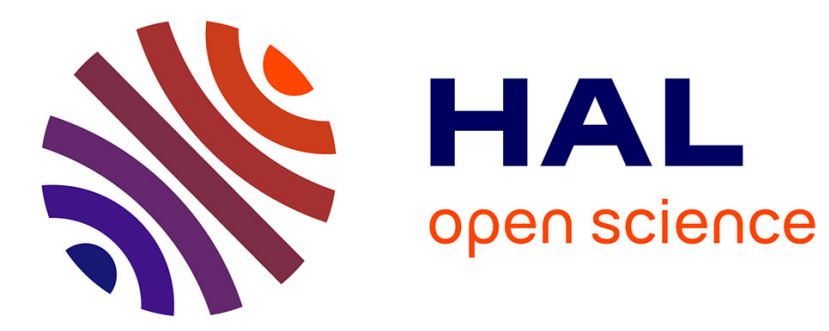

\title{
MAGNETISATION DENSITY IN Pd2MnSb
}

S. Johnson, J. Bland, P. Brown, P. Webster, K. Ziebeck

\section{To cite this version:}

S. Johnson, J. Bland, P. Brown, P. Webster, K. Ziebeck. MAGNETISATION DENSITY IN Pd2MnSb. Journal de Physique Colloques, 1982, 43 (C7), pp.C7-119-C7-124. 10.1051/jphyscol:1982718 . jpa00222325

\section{HAL Id: jpa-00222325 https://hal.science/jpa-00222325}

Submitted on 1 Jan 1982

HAL is a multi-disciplinary open access archive for the deposit and dissemination of scientific research documents, whether they are published or not. The documents may come from teaching and research institutions in France or abroad, or from public or private research centers.
L'archive ouverte pluridisciplinaire HAL, est destinée au dépôt et à la diffusion de documents scientifiques de niveau recherche, publiés ou non, émanant des établissements d'enseignement et de recherche français ou étrangers, des laboratoires publics ou privés. 
JOURNAL DE PHYSTQUE

Colzoque C7, supplément au n²12, Tome 43, décembre 1982

page $67-119$

MAGNETISATION DENSITY IN $\mathrm{Pd}_{2} \mathrm{MnSb}$

S.M. Johnson, J.A.C. Bland*, P.J. Brown, P.J. Webster ${ }^{* *}$ and K.R.A. Ziebeck

Institut Lraue-Langevin, $156 \mathrm{X}$ Centre de Tri, 38042 Grenoble Cedex, France

* Department of Physics, University of Cambridge, Cambridge, CB3 OHE, U.K.

* Department of Pure and Applied Physics, University of Salford, Salford MS 4 WT, U.K.

Résumé. - Les facteurs de structure, le facteur de forme magnétique et la distribution spatiale de la densité d'aimantation dans le composé $\mathrm{Pd} 2 \mathrm{MnSb}$ ont été déterminés par des mesures de diffraction de neutrons polarisés faites sur le diffractomètre D3 de 1'I.L.L. On observe un moment ferromagnétique important essentiellement localisé sur les sites ordonnés des Mn. Le facteur de forme magnétique est en bon accord avec celui calculé par Watson et Freeman pour les ions $\mathrm{Mn}^{++}$. Un moment magnétique équivalent mais de signe opposé est observê sur le petit nombre d'atomes Mn occupant une position desordonnée (sites Sb). On n'observe pas de moment mesurable sur les sites du Pd.

Abstract. - The structure factors, magnetic form factor and the spatial distribution of the magnetisation density in $\mathrm{Pd}_{2} \mathrm{MnSb}$ have been studied by polarised neutron diffraction using the D3 diffractometer at I.L.L. The large ferromagnetic moment observed is essentially localised at the ordered Mn sites and the magnetic form factor is in good agreement with that for $\mathrm{Mn}^{++}$ions calculated by Watson and Freeman. An equivalent but negative moment is observed on the sma 11 proportion of disordered $\mathrm{Mn}$ atoms occupying $\mathrm{Sb}$ sites. No measurable moment was observed on the Pd sites.

1. Introduction. - The Heusler alloys are ternary intermetallic compounds with the L21 structure indicated in figure 1. They are an interesting series for magnetic investigation because they offer an opportunity for determining the effects of interatomic distance, atomic arrangement and electron concentration on the occurence and type of magnetic order in 3 d metallic systems.

The original Heusler alloys were all ferromagnetic and based on the composition Cu2 $\mathrm{MnZ}$, where $Z$ is an sp element in sub-group 3,4 or 5 . Later a number of isostructural alloys, in which nickel or cobalt was substituted for copper, were also discovered. The latter however, from a theoretical viewpoint, suffer from the comp $1 \mathrm{i}$ cation of containing a constituent that in its elemental state is strongly ferromagnetic.

In 1960, in a search for further examples of Heusler type alloys, Hames [1] reported two new intermetallic compounds containing palladium, $\mathrm{PdMnSb}$ and $\mathrm{Pd} 2 \mathrm{MnSb}$. The former was a strong ferromagnet but the latter responded only feebly to an external magnetic field at room temperature. Hames tentatively concluded, from $X$-ray powder photographs, that $\mathrm{Pd}_{2} \mathrm{MnSb}$ had the Heusler structure and $\mathrm{PdMnSb}$ the $\mathrm{C}_{\mathrm{b}}$ structure. The latter structure is similar to the $L 2 \uparrow$ but with alternate former Pd sites replaced by ordered vacancies. Webster and Tebble [2] made detailed magnetic, $\mathrm{X}$-ray and neutron diffraction measurements on polycrystalline samples of $\mathrm{Pd} 2 \mathrm{MnSb}$. They showed that at low temperatures the material was indeed ferromagnetic with a Curie temperature $247 \mathrm{~K}$ and a saturation moment $4.40 \mu_{\mathrm{B}}$. The combined $\mathrm{X}$-ray and neutron diffraction data confirmed that the constituents were highly ordered in the Heusler structure. The Tattice parameter was measured as 6.42 A giving a nearest $\mathrm{Mn}-\mathrm{Mn}$ separation of $4.5 \mathrm{~A}$, the largest then known in Heusler alloys. The neutron data also indicated that to with in the limits of measurement, which was approximately $\pm 0.2 \mu_{\mathrm{B}}$, the entire moment appeared to be associated with the Mn sites. 
HEUSLER (L2 ${ }_{1}$ ) STRUCTURE OF $\mathrm{Pd}_{2} \mathrm{MnSb}$
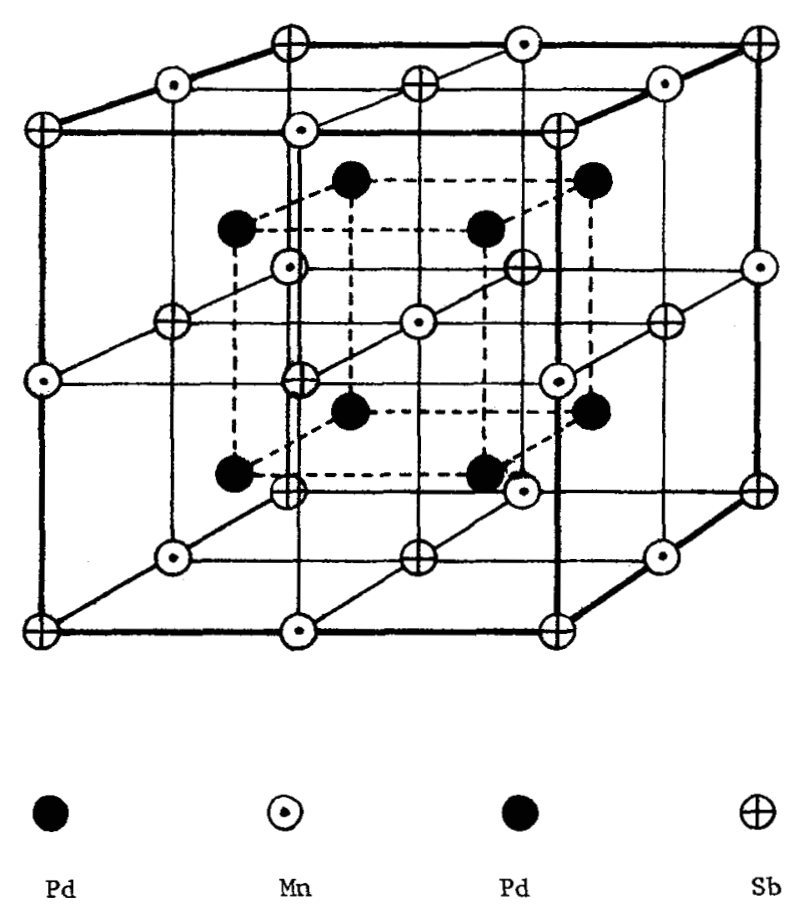

$$
\begin{aligned}
& \mathrm{F}^{2}(111)=16(\mathrm{Mn}-\mathrm{Sb})^{2} \\
& \mathrm{~F}^{2}(200)=16|2 \mathrm{Pd}-(\mathrm{Mn}+\mathrm{Sb})|^{2} \\
& \mathrm{~F}^{2}(200)=16|2 \mathrm{Pd}+(\mathrm{Mn}+\mathrm{Sb})|^{2}
\end{aligned}
$$

Fig. 1 
The Mn-Mn separation in Heusler alloys in general, and $\mathrm{Pd}_{2} \mathrm{MnSb}$ in particular, are so large that direct $d-d$ overlap is negligible and the magnetic coupling must be indirect via the conduction electrons or via a superexchange. For a particular theoretical interpretation to be soundly based,accurate measurements of the spin density distribution are required.

Ishikawa et a]. [3], using the D5 polarised neutron spectrometer at the ILL, made measurements on a single crystal close to the composition $\mathrm{Pd} 2 \mathrm{MnSn}$. Although the experimental conditions were not optimal they were able to conclude that the moment was largely localised at the Mn sites and that the form factor was adequately described by the $\mathrm{An}^{++}$ionic form factor calculated by Watson and Freeman [4]. They also concluded that the $\mathrm{Pd}$ sites had a small positive polarisation $0.1 \pm 0.05 \mu_{\mathrm{B}}$ and that there was possibly a small negative polarisation at the $S n$ sites $\leqslant 0.1 \mu_{B}$. However, both these moments were close to the 1 imits of accuracy of the measurements. Results are presented here of a polarised neutron investigation of a single crystal of $\mathrm{Pd}_{2} \mathrm{MnSb}$.

2. Experimental details. - A single crystal ingot of the intermetallic compound $\mathrm{Pd} 2$ WnSb was grown from the melt, by Perrier de la Bathie at C.N.R.S., Grenoble, using the Bridgman technique. A pillar shaped specimen, of dimensions $5 \times 5 \times 10 \mathrm{~mm}$, was cut out such that a $\langle 1 \bar{I} 0\rangle$ zone axis was along the long axis of the pillar. The crystal was then mounted on an aluminium pin and inserted at the centre of a 4.8 Tesla asymmetric split pair superconducting magnet located on the D3 polarised neutron diffractometer at ILL, Grenoble. The temperature was maintained at $30 \mathrm{~K}$ and the incident wavelength was $0.9 \AA$.

Flipping ratio measurements, $R$, were measured for all reflections hke out to $(\sin \theta) / \lambda=0.94 \AA^{-1}$ in the zero and first layers. In addition to the polarisation ratio measurements, measurements were made of a series of integrated intensities of independent reflections in order to determine the degree of chemical order in the sample.

3. Results and discussions. - After a least squares refinement the following scattering amplitudes were obtained for the three atomic sites

$$
\begin{aligned}
& b_{P d}=0.65 \pm 0.04 \mathrm{~cm}^{-1} \\
& b_{M n}=-0.31 \pm 0.02 \mathrm{~cm}^{-1} \\
& b_{S b}=0.50 \pm 0.03 \mathrm{~cm}^{-1}
\end{aligned}
$$

with an $\mathrm{R}$ factor of nuclear refinement $7 \%$.

The average site moments, obtained from the flipping ratio measurements were

$$
\begin{aligned}
& \mu_{P d}=0.02 \pm 0.01 \mu_{B} \\
& \mu_{M n}=4.58 \pm 0.07 \mu_{B} \\
& \mu_{S b}=-0.18 \pm 0.01 \mu_{B}
\end{aligned}
$$

with an $R$ factor of magnetic refinement $4 \%$.

A Fourier section at the origin in the (110) plane of the measured magnetisation density is shown in figure 2(a). Figure 2(b) shows the equivalent calculated section assuming a Clementi wave function [5] appropriate to a $\mathrm{Mn}^{++}$ion in the dipole approximation. Figure 3(a) shows the difference map $F_{\text {obs }}-F_{c a l c}$, scaled up by a factor of 10. Figure 3(b) shows an equivalent difference map using a model in which the appropriate $\mathrm{Sb}$ wave function was used for the $\mathrm{Sb}$ sites.

The measured nuclear scattering amplitudes for the 3 sites indicate that the palladium is highly ordered but that there is $4.6 \pm 0.7 \% \mathrm{Mn}-\mathrm{Sb}$ disorder on the other two sites. The spin density maps show that the large ferromagnetic monent is localised at the ordered Mn sites and is essentially spherically symmetric. There is also a smal1 negative moment at the 'Sb' sites. However, the difference maps clearly show that the negative density is more extended than that calculated using the $\mathrm{Sb}$ 


PDZMNSB MAGNETIC DENSITY TEMP $=30 \mathrm{~K}$

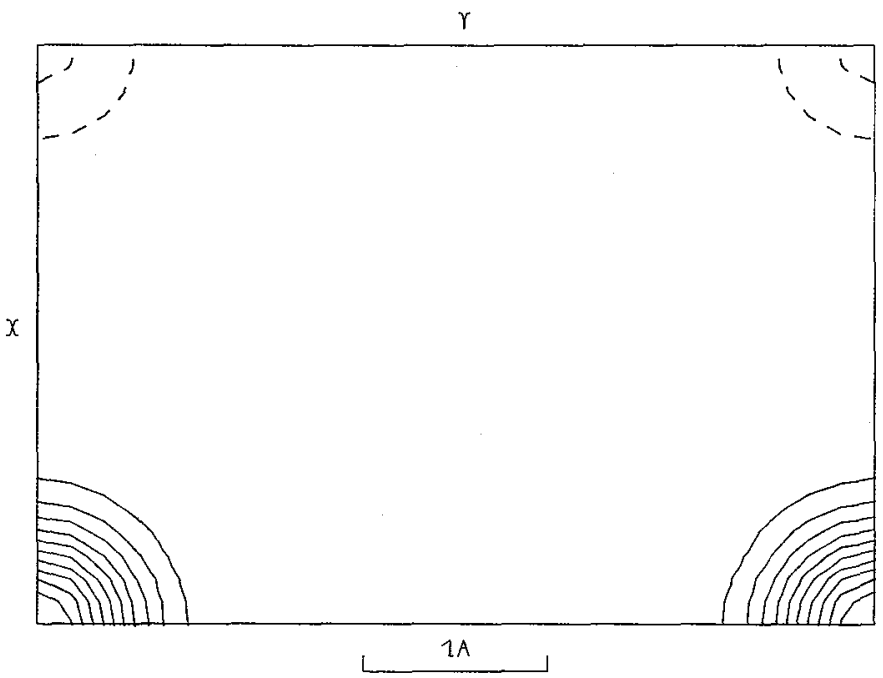

Fig. 2(a)

\begin{tabular}{|c|}
\hline CONTOURS \\
\hline 50 \\
100 \\
150 \\
200 \\
250 \\
300 \\
350 \\
400 \\
450 \\
500 \\
450 \\
450 \\
-50 \\
-25 \\
\hline
\end{tabular}

\begin{tabular}{|cccccccc|}
\hline FOURIER SECTIDN AT & & 0 & ON & \multicolumn{3}{c|}{100010000} \\
\hline$X$ PARALLEL TO & 0 & 0 & 1 & FROM & 0 & TO & 0.5 \\
Y PARALLEL TO & 1 & 1 & 0 & FROM & 0 & TO & 0.5 \\
\hline COEFFICIENTS ARE & FOBS & MULT IPLIED & BY & 100 \\
AND AVERAGED OUER A CUBE OF EDGE & 0.5 & \\
\hline
\end{tabular}

PDZMNSB MAGNETIC DENSITY TEMP $=30 \mathrm{~K}$

$\gamma$

Fig. 2(b)

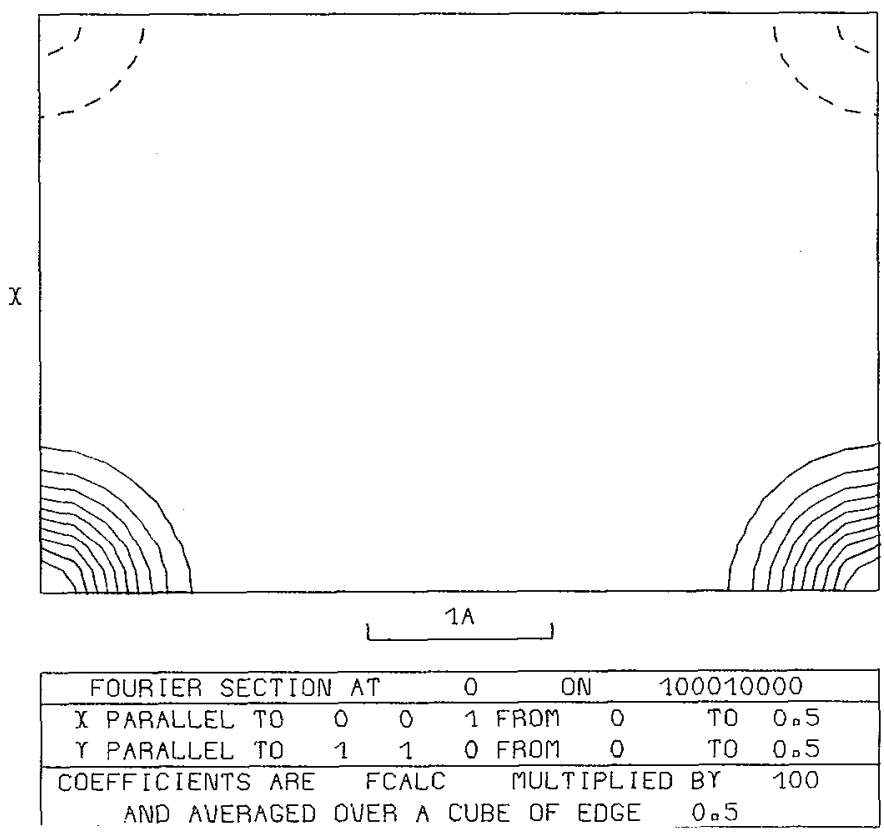

\begin{tabular}{|c|}
\hline CONTOURS \\
\hline 50 \\
100 \\
150 \\
200 \\
250 \\
300 \\
350 \\
400 \\
450 \\
500 \\
450 \\
450 \\
-50 \\
-25 \\
\hline
\end{tabular}



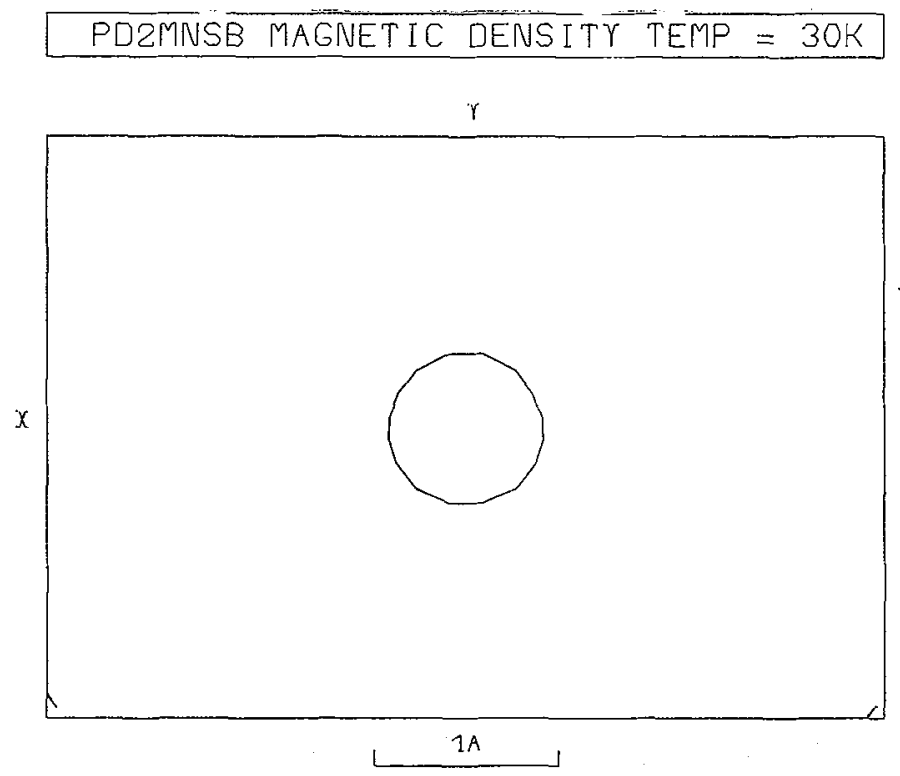

Fig. 3(a)

\begin{tabular}{|c|}
\hline CONTOURS \\
\hline 50 \\
25 \\
\hline
\end{tabular}

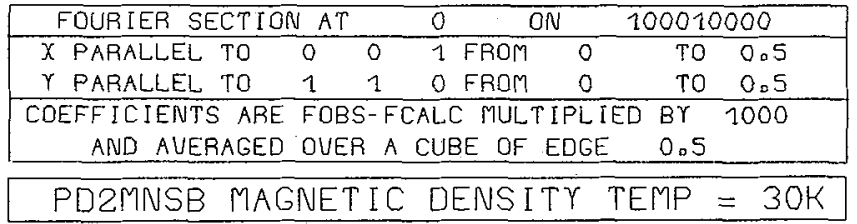

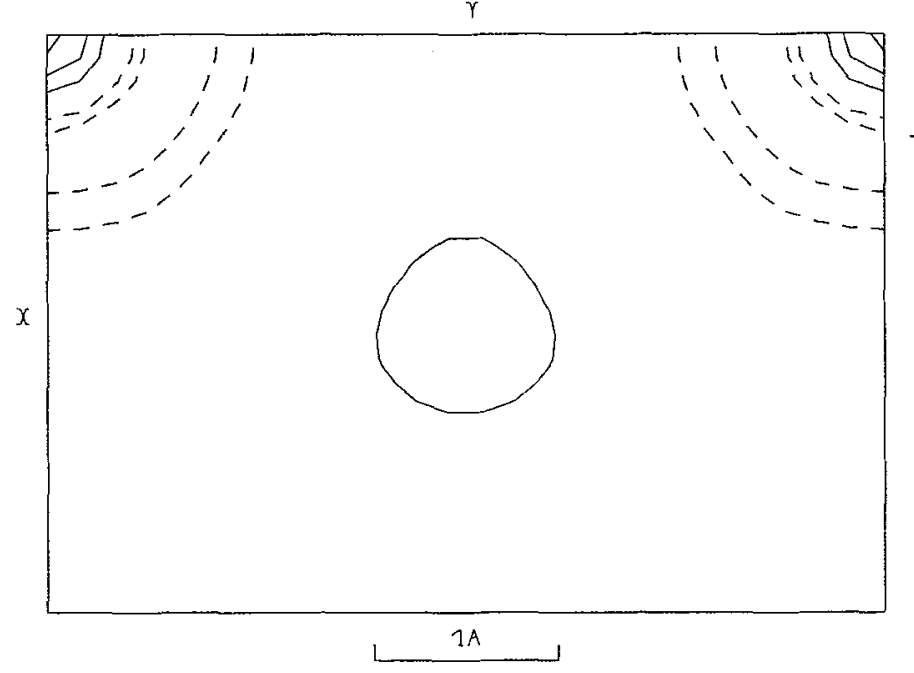

Fig. 3(b)

\begin{tabular}{|c|}
\hline CONTOUAS \\
\hline 50 \\
100 \\
150 \\
-50 \\
-25 \\
\hline
\end{tabular}

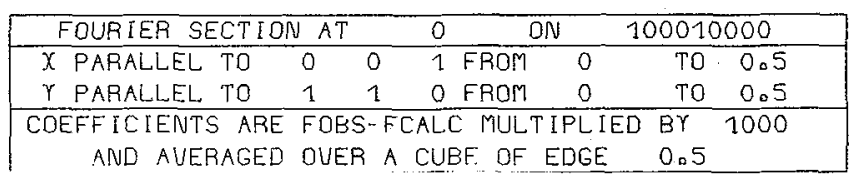


wave functions, but is wel1 represented by that.predicted using the Mn wave functions. Additionally, magnitude and sign are exactly what would be expected for $4 \% \mathrm{Mn}$ occupancy of the ' $S b^{\prime}$ sites, with a moment of $4.58 \mu_{\mathrm{B}}$ aligned antiparallel to the moment on the ordered Mn site. This is in agreement with the observations of the Le Dang Khoi et a]. [6] from hyperfine field measurements, that in general Mn at the disordered site has a similar moment to the Mn on the regular site but with opposite sign.

Gyromagnetic ratios were determined using the dipole approximation for Mn at the regular and disordered sites. The values obtained were

$$
\begin{aligned}
& g_{M n}=2.03 \pm 0.04 \\
& \text { and } g_{S^{\prime} b^{\prime}}=2.24 \pm 0.20
\end{aligned}
$$

which, within the experimental error, do not differ from $g=2$ indicating the $a b-$ sence of any significant orbital contribution. The fractions of electrons occupying orbitals of $e_{g}$ symmetry were determined to be $0.45 \pm 0.05$ and $0.41 \pm 0.1$ for the regular and disordered sites respectively. For complete spherical symmetry the $e_{g}$ occupation fraction should be 0.40 .

In summary, the entire moment in $\mathrm{Pd}_{2} \mathrm{MnSb}$ is localised on the Mn sites, is entirely spin in origin and is spherically symmetric. Any Mn atoms occupying ' $S b^{\prime}$ sites are aligned antiparallel to the Mn site moments.

Ishikawa et al. [3] pointed out that $\operatorname{Pd} 2 \mathrm{MnSn}$, when cooled, was a better polariser than $\mathrm{Cu}_{2} \mathrm{MnAl}$. Pd2 $\mathrm{Mn}^{\mathrm{MS} b}$ has a slightly greater moment than $\mathrm{Pd}_{2} \mathrm{MnSn}$ and polarises just as well 1 but at a higher temperature. The series $\mathrm{Pd}_{2-x} \mathrm{MnSb}$, for different values of $x$ in the range $0<x<1$, can be made to polarise on the (111), (002), (220) or (222) reflections at temperatures between 100 and $300 \mathrm{~K}$ [7].

\section{References}

[1] Hames, F.A., J. Appl. Phys. 31 (1960) 370.

[2] Webster, P.J. and Tebble, R.S., Phi]. Mag. 16 (1967) 347.

[3] Ishikawa, Y., Tajima, K. and Radhakrishna, P., J. Phys. Soc. Japan 40 (1976) 1597

[4] Watson, R.E. and Freeman, A.J., Acta Cryst. 14 (1961) 27.

[5] Clementi, E. and Roetti, C., Atomic and nuclear data tables 14 (1974) 177.

[6] Le Dang Khoi, Veillet, P. and Campbel1, I.A., J. Phys. F. 8 (1978) 1811.

[7] Brown, P.J., Ziebeck, K.R.A., Bland, J.A.C. and Webster, P.J., J. Phys. D. 14 (1981) 511. 